\title{
Three-Dimensional Scaffolds Reduce Islet Amyloid Formation and Enhance Survival and Function of Cultured Human Islets
}

\author{
Yun Zhang, Reza B. Jalili, Garth L. Warnock, \\ Ziliang Ao, Lucy Marzban, and Aziz Ghahary \\ From the Department of Surgery, Faculty of Medicine, University \\ of British Columbia, Vancouver, British Columbia, Canada
}

Islet transplantation provides a promising approach for treatment of type 1 diabetes mellitus. Amyloid formation and loss of extracellular matrix are two nonimmune factors contributing to death of isolated human islets. We tested the effects of two types of three-dimensional scaffolds, collagen matrix (CM) and fibroblast-populated collagen matrix (FPCM), on amyloid formation, viability, and function of isolated islets. Islets from cadaveric donors were cultured in FPCM, CM, or two-dimensional plate (2D) for 7 days. After 7 days, compared with the 2D culture condition, CM and FPCM markedly reduced amyloid formation of cultured islets and decreased apoptotic $\beta$-cell rate by $\sim 75 \%$. IL-1 $\beta$ and Fas levels were also reduced in scaffold-embedded islets. Furthermore, $\beta / \alpha$ cell ratios were increased by $\sim 18 \%$ and $\sim 36 \%$ in CM- and FPCMembedded islets, respectively. Insulin content and insulin response to elevated glucose were also enhanced by both three-dimensional scaffolds. Moreover, culture in CM and FPCM (but not 2D) preserved insulin, GLUT-2, and PDX-1 mRNA expression. FPCM-embedded islets had significantly higher insulin response and lower amyloid formation than CM-embedded islets. These findings suggest that three-dimensional scaffolds reduce amyloid formation and improve viability and function of human islets in vitro, and that $\mathrm{CM}$ and fibroblasts have additive effects in enhancing islet function and reducing amyloid formation. Using this strategy is likely to improve outcome in human islet transplantation. (AmJ Pathol 2012, 181:1296-1305; bttp:// dx.doi.org/10.1016/j.ajpath.2012.06.032)

Type 1 diabetes mellitus is an autoimmune disease characterized by progressive destruction of pancreatic islet $\beta$ cells, leading to insulin deficiency, elevated plasma glu- cose level, and lifelong insulin therapy. ${ }^{1,2}$ In the past decade, replacement of pancreatic $\beta$ cells with human islet transplantation has provided a feasible approach for treatment of patients with type 1 diabetes mellitus. ${ }^{3-5}$ However, human islet transplantation is currently limited by low numbers of available pancreatic donors, loss of a significant number of islets during islet isolation and after transplantation, and poor long-term survival of islet grafts. ${ }^{6,7}$ A study from the Edmonton Group showed that, although $80 \%$ of human islet graft recipients achieve insulin independence during the first year, only $10 \%$ of patients remain insulin independent by 5 years after transplantation. ${ }^{4}$ Both immune and nonimmune factors contribute to reduced $\beta$-cell mass and function in transplanted islets, which eventually leads to islet graft failure. ${ }^{6}$

Nonimmune-mediated islet $\beta$-cell death occurs during the various steps of islet transplantation, including islet isolation, culture, and implantation. ${ }^{6,8,9} \mathrm{~A}$ considerable number of islets are lost during the pretransplant culture period, ${ }^{10-12}$ as well as in the first days after transplantation. ${ }^{13-15}$ Formation of islet amyloid toxic protein aggregates and loss of islet extracellular matrix are two important nonimmune factors that contribute to $\beta$-cell dysfunction and death both during pretransplant islet culture ${ }^{11}$ and in islet grafts. ${ }^{16}$

Islet amyloid, formed by aggregation of islet amyloid polypeptide, is a pathological characteristic of the pancreas in type 2 diabetes mellitus that contributes to progressive $\beta$-cell death in this disease. ${ }^{17}$ Several studies have shown that toxic islet amyloid polypeptide aggregates also form in cultured and transplanted human islets. ${ }^{11,16}$ Similar to that seen in type 2 diabetes mellitus, formation of islet amyloid in both cultured and trans-

Supported by the Canadian Institutes of Health Research (A.G. and L.M.). R.B.J. was supported by a Juvenile Diabetes Research Foundation Fellowship.

Accepted for publication June 20, 2012.

Address reprint requests to Aziz Ghahary, Ph.D., Department of Surgery, Faculty of Medicine, University of British Columbia, Room 4550, ICORD, 818 West 10th Ave., Vancouver, BC, V5Z 1M9, Canada. E-mail: aghahary@mail.ubc.ca. 
planted human islets is associated with $\beta$-cell dysfunction and death and contributes to islet graft failure. ${ }^{16-18}$

Digestion of pancreatic tissue during the islet isolation process disturbs the structure of the islet extracellular matrix, which has an important role in maintaining both islet viability and function. ${ }^{19-22}$ We previously developed a composite scaffold that consists of fibroblasts embedded within collagen matrix. ${ }^{23}$ In this model, the collagen provides surrogate extracellular matrix materials for islets and the fibroblasts maintain the scaffold structure and release different growth factors. ${ }^{24}$ In the present study, we used human islets isolated from cadaveric pancreatic donors to test whether collagen matrix (CM) alone or human fibroblast-populated collagen matrix (FPCM) can reduce formation of $\beta$-cell toxic amyloid aggregates in human islets during culture and enhance islet viability and function.

\section{Materials and Methods}

\section{Preparation of Human Fibroblasts}

Human fibroblasts were explanted from foreskin samples of infants in accordance with the ethical guidelines set forth by the University of British Columbia. Briefly, foreskin samples from infants undergoing elective circumcision were obtained under local anesthesia. Skin samples were washed six times in sterile $1 \times$ PBS supplemented with a $1 \%$ antibiotic-antimycotic mixture (100 $\mu \mathrm{g} / \mathrm{mL}$ penicillin, $100 \mu \mathrm{g} / \mathrm{mL}$ streptomycin, and $0.25 \mu \mathrm{g} / \mathrm{mL}$ amphotericin B) (Life Technologies-Invitrogen, Auckland, New Zealand). Epidermal and dermal layers were separated by treatment with dispase (40 mg/mL; Life Technologies-Invitrogen) for 2 hours at $37^{\circ} \mathrm{C}$. After removal of the epidermal layer, dermal tissues were minced into small pieces ( 1 to $2 \mathrm{~mm}$ in diameter) and transferred into $60 \times 15$-mm Petri dishes, and fibroblasts were cultured as described previously. ${ }^{25}$ Cultured fibroblasts ( $~ 80 \%$ confluent) were trypsinized and cultured in $75-\mathrm{cm}^{2}$ culture flasks. Passages 3 to 7 of cultured fibroblasts were used for the experiments.

\section{Culture of Human Islets}

Human islets isolated from cadaveric pancreatic donors were received from the Ike Barber Human Islet Transplant Laboratory (Vancouver, BC, Canada) in accordance with approved procedures and guidelines of the Clinical Research Ethics Board of the University of British Columbia. Islets were hand-picked, and islet purity was assessed by dithizone staining. Human islets (purity $\sim 90 \%$ ) were then cultured in noncoated 48-well plates under three different conditions: free-floating in Ham's/ F10 medium (Sigma-Aldrich, St. Louis, MO), embedded within collagen matrix/Ham's/F10 (CM), or embedded within fibroblast-populated collagen matrix/Ham's/F10 (FPCM). For all three conditions, islets were cultured for 7 days in a humid atmosphere $\left(95 \%\right.$ air, $\left.5 \% \mathrm{CO}_{2}\right)$ at $37^{\circ} \mathrm{C}$. Ham's/F10 medium was supplemented with $6 \mathrm{mmol} / \mathrm{L}$ glucose, $12 \mathrm{mmol} / \mathrm{L}$ HEPES, $2 \mathrm{mmol} / \mathrm{L}$ L-glutamine, 10\% heat-inactivated fetal calf serum, $100 \mathrm{U} / \mathrm{mL}$ penicillin, and $100 \mu \mathrm{g} / \mathrm{mL}$ streptomycin. The medium was replaced every 48 hours. For amyloid studies, islets were cultured in high-glucose ( $16 \mathrm{mmol} / \mathrm{L}$ ) medium from day 4 to day 7 , to potentiate islet amyloid formation in human islets.

\section{Preparation of FPCM and CM Islet Composites}

$\mathrm{CM}$ and FPCM were established as described previously, ${ }^{23}$ with some modifications. Briefly, CM for islet culture was prepared by adding $60 \mu \mathrm{L}$ of $3 \times \mathrm{Ham}$ 's/F10 medium (Sigma-Aldrich), $10 \mu \mathrm{L}$ of $0.1 \mathrm{~mol} / \mathrm{L} \mathrm{NaOH}, 21 \mu \mathrm{L}$ of fetal bovine serum (Life Technologies-Invitrogen), and $150 \mu \mathrm{L}$ of $5 \mathrm{mg} / \mathrm{mL}$ acid-extracted fetal bovine type I collagen (Sigma-Aldrich) per well in 48-well plates (final collagen concentration: $2.4 \mathrm{mg} / \mathrm{mL}$ ). To prepare FPCM, $10^{4}$ human fibroblasts were added to the collagen matrix just described. Human islets (100 islets/well) were then added to each well containing either CM or FPCM before solidification of the collagen.

\section{Islet Viability Assay}

Islet cell viability was assessed by a viability/cytotoxicity assay kit (Life Technologies-Invitrogen, Eugene, OR) according to the manufacturer's instructions. Briefly, islet samples (100 islets/well) were incubated with the working solution containing ethidium homodimer-1 (4 mmol/L) and calcein AM ( $2 \mathrm{mmol} / \mathrm{L})$ in $1 \times$ PBS for 30 minutes at room temperature under dark conditions. Islets were examined under an Axiovert 200M fluorescence microscope (Carl Zeiss, Oberkochen, Germany). Live cells with intact membrane were detected by the green fluorescence generated by ubiquitous intracellular esterase in those cells; dead cells with damaged membrane were detected by ethidium homodimer-1 staining (red fluorescence). The proportion of live and dead islet cells were analyzed by flow cytometry performed on dispersed islet cells.

\section{Glucose-Stimulated Insulin Secretion}

FPCM and CM composites were digested by incubating composites in type I collagenase solution $(4 \mathrm{mg} / \mathrm{mL}$; Sigma-Aldrich) at $37^{\circ} \mathrm{C}$ for 5 minutes. Collagenase activity was then stopped by adding supplemented Ham's/ F10 medium and human islets were hand-picked from digested matrices under a microscope. Islets (50 islets/ well, duplicate) were then preincubated (1 hour) in Krebs-Ringer bicarbonate buffer containing $10 \mathrm{mmol} / \mathrm{L}$ HEPES (pH 7.4), $0.25 \%$ bovine serum albumin, and 1.67 $\mathrm{mmol} / \mathrm{L}$ glucose in 48 -well plates at $37^{\circ} \mathrm{C}$, followed by 1 hour incubation in Krebs-Ringer bicarbonate buffer containing either $1.67 \mathrm{mmol} / \mathrm{L}$ glucose (basal insulin release) or $16.7 \mathrm{mmol} / \mathrm{L}$ glucose (glucose-stimulated insulin release). Human islets in each well were lysed in $100 \mu \mathrm{L}$ lysis buffer containing $1 \mathrm{~mol} / \mathrm{L} \mathrm{HCl}$ and $0.1 \%$ bovine serum albumin. The incubation medium and islet lysates were collected and centrifuged $(13,000 \times g)$ for 10 minutes at $4^{\circ} \mathrm{C}$, and the supernatants were frozen at $-20^{\circ} \mathrm{C}$ until assayed. Insulin levels in medium and islet lysates were measured using a human specific insulin enzyme-linked immunosorbent assay (ELISA) kit (Alpco Diagnostics, Salem, NH). 


\section{Immunohistochemistry and Detection of Islet Amyloid}

Paraffin-embedded sections $(5 \mu \mathrm{m})$ of islets cultured in Ham's/F10 (two-dimensional), acellular CM, or FPCM were deparaffinized and hydrated by incubation in xylene and ethanol. To retrieve cell surface antigens, a steamer heating pretreatment was performed before blocking with $1 \%$ bovine serum albumin (Sigma-Aldrich) and 2\% normal goat serum (Sigma-Aldrich) in PBS ( $\mathrm{pH}$ 7.4). For double immunostaining for insulin and glucagon, islet sections were incubated with guinea pig anti-insulin antibody (1:750 dilution; Dako, Carpinteria, CA) and rabbit anti-glucagon antibody (1:750 dilution; Dako) at $4^{\circ} \mathrm{C}$ overnight, then rinsed with PBS and incubated with Texas Red-conjugated anti-guinea pig antibody (1:750 dilution; Jackson Laboratories, West Grove, PA) and Alexa Fluor 488-conjugated goat anti-rabbit antibody (1:750 dilution; Jackson Laboratories) for 1 hour at room temperature. Sections were then mounted with a mounting medium containing nuclear dye DAPI (Vector laboratories, Burlingame, CA). For double immunostaining for insulin and cleaved (active) caspase-3, islet sections were incubated with guinea pig anti-insulin antibody (1:500 dilution; Dako) and rabbit anti-cleaved caspase-3 antibody (1:100 dilution; R\&D Systems, Burlington, ON) at $4^{\circ} \mathrm{C}$ overnight, followed by incubation with fluorescein isothiocyanate-conjugated goat anti-guinea pig IgG (1: 1000 dilution; Abcam, Cambridge, MA) and rhodamine-conjugated anti-rabbit IgG (1:1000 dilution; Chemicon International, Temecula, CA) for 45 minutes at room temperature. For detection of islet amyloid, islet sections were immunostained for insulin as detailed above, followed by incubation with $0.5 \%(\mathrm{w} / \mathrm{v})$ thioflavin $\mathrm{S}$ solution (Sigma-Aldrich) for 5 minutes at room temperature. For triple immunostaining for insulin, either IL-1 $\beta$ or Fas, and thioflavin $\mathrm{S}$, islet sections were immunolabeled overnight for insulin (1:750 dilution) and IL-1 $\beta$ (1:100 dilution; Santa Cruz Biotechnology, Santa Cruz, CA) or Fas (1:100 dilution; Cell Signaling Technology, Pickering, ON, Canada), followed by incubation with Texas Red-conjugated anti-guinea pig (1:750 dilution; Jackson Laboratories) and Alexa Fluor 488-conjugated goat anti-rabbit (1:100 dilution for IL-1 $\beta$ staining; 1:200 dilution for Fas staining). Islet sections were then incubated for 5 minutes at room temperature with $0.5 \%$ thioflavin $S$ solution. For triple immunostaining for insulin, cleaved (active) caspase- 3 , and thioflavin $S$, islet sections were incubated with guinea pig anti-insulin (1:500 dilution; Dako) and rabbit anti-cleaved caspase-3 (1:100 dilution; R\&D systems) antibodies at $4^{\circ} \mathrm{C}$ overnight, followed by incubation with fluorescein isothiocyanateconjugated goat anti-guinea pig IgG (1:1000 dilution; Abcam) and rhodamine-conjugated anti-rabbit IgG (1: 1000 dilution; Chemicon International). Islet sections were then incubated for 5 minutes at room temperature with $0.5 \%$ thioflavin S solution. Islet images were captured using a Zeiss Axioplan 2 microscope and AxioVision image analysis software.

\section{$R T-P C R$}

CM and FPCM composites were digested using type I collagenase (4 mg/mL; Sigma-Aldrich) as described above, and islets were hand-picked from cell suspensions. Total RNA was isolated from human islets using an RNeasy kit (Qiagen, Valencia, CA). cDNA was synthesized using SuperScript first-strand synthesis system for RT-PCR (Life Technologies-Invitrogen). Polymerase chain reaction $(P C R)$ was then performed using primers sequences as follows: insulin forward 5'-AGGCCATCAAGCAGATCACTGTCCT-3', reverse 5'-ACGCTTCTGCAGGGACCCCT-3'; PDX1 forward 5'-GGCGTCCTGGAGGAGCCCAA-3', reverse 5'-GGCGCGGCCGTGAGATGTAC-3'; GLUT2 forward 5'TTGGTGGGTGGCTTGGGGAC-3', reverse 5' -TCCCCTGAGAGCGGTTGGAGC-3'; Fas forward 5'-GCTGGGCATCTGGACCCTCCT-3', reverse 5'-TTGGCAGGGCACGCAGTCTG-3'; and GAPDH forward 5' -GGCATTGCTCTCAATGACAA-3', reverse: 5'-TGTGAGGGAGATGCTCAGTG-3'. Amplified PCR products were then separated by $1 \%$ agarose gel electrophoresis and visualized with SYBR Safe DNA gel staining (Life Technologies-Invitrogen) under UV light.

\section{Statistical Analysis}

Data are expressed as means \pm SEM. Statistical analyses were performed using one-way analysis of variance, followed by post hoc multiple comparison tests. $P<0.05$ was taken as significant. All experiments were performed in triplicate and were repeated three times.

\section{Results}

\section{Three-Dimensional Scaffolds Improve Viability of Human Islets during in Vitro Culture}

Before evaluating the effect of scaffolds on amyloid formation in human islets, we conducted a series of experiments to evaluate islet viability and function in these three-dimensional systems. To examine the effects of the three-dimensional scaffold and the potential role of fibroblasts in enhancing islet survival in human islets, isolated human islets were embedded within collagen matrix with human fibroblasts (FPCM) or without (CM). Free-floating human islets cultured in standard two-dimensional culture plates were used as control. Islet morphology was monitored during culture, and viability testing was performed on islets before and after 7 days culture under each condition. Embedding human islets within both CM and FPCM preserved normal islet morphology, whereas two-dimensional cultured islets gradually lost their normal morphology during culture (Figure 1A). Furthermore, detection of live and dead islet cells by calcein $\mathrm{AM}$ and ethidium homodimer-1 staining showed that both CM- and FPCM-embedded human islets had significantly lower numbers of dead cells, compared with those in two-dimensional cultured islets (Figure 1A). These findings were further confirmed by quantification of dead islet cells by flow cytometry performed on dispersed human islet cells from each culture condition (Figure 1, B and C). Islet cell viability was $\sim 90 \%$ before culture and was re- 

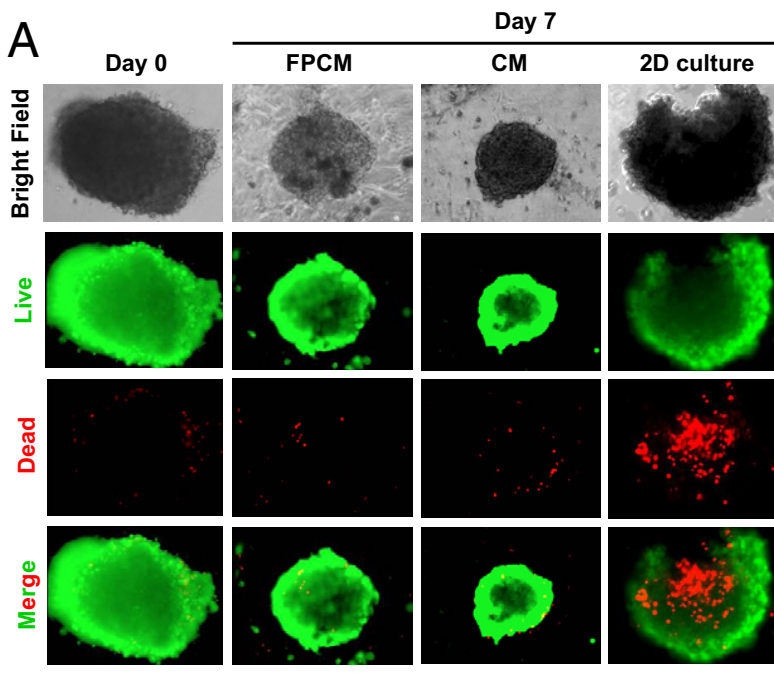

B

Day 7
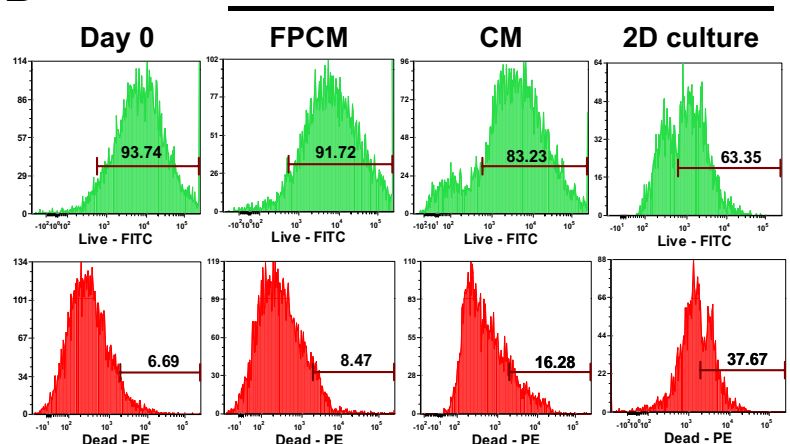

C

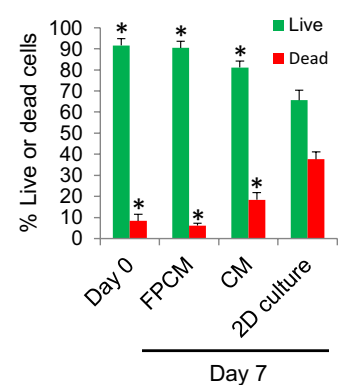

Figure 1. Three-dimensional scaffolds improve viability of cultured human islets. Human islets were cultured in three-dimensional fibroblast-populated collagen matrix (FPCM), collagen matrix (CM), or two-dimensional (2D) Ham's/F10 medium. Islet cell viability was assessed preculture (day 0) and after 7 days of culture using a live/dead viability/cytotoxicity assay kit. A: Islet morphology and viability. Note loss of normal islet morphology during two-dimensional culture (bright-field images, taken under inverted microscope). Live islet cells are shown in green, dead islet cells in red. B: Representative histograms of flow cytometry assays performed on dispersed human islet cells. C: Quantification of live and dead islet cells in twodimensional and three-dimensional cultured human islets by flow cytometry. Data are expressed as means \pm SEM of three independent experiments performed in triplicate $(\mathbf{C}) .{ }^{*} P<0.01$ versus two-dimensional cultured islets, one-way analysis of variance. Original magnification, $\times 400$.

duced to $63 \%$ in two-dimensional cultured islets after 7 days of culture, whereas cell viability in CM- and FPCMembedded islets was $\sim 83 \%$ and $\sim 92 \%$, respectively. Maintenance of cell viability in three-dimensional scaffold cultured islets closely correlated with a reduced number of dead cells in CM ( 16\%) and FPCM ( 8\%) cultured islets, compared with two-dimensional cul- tured islets $(\sim 38 \%)$. There was no significant difference in cell viability between CM- and FPCM-embedded human islets.

\section{Human Islets Embedded within Three-}

Dimensional Scaffolds Have Lower $\beta$-Cell

Apoptosis and Higher Islet $\beta / \alpha$ Cell Ratio

Compared with Two-Dimensional Cultured Islets

To identify whether the dead islet cells detected with ethidium homodimer-1 staining were $\beta$ cells, paraffinembedded islet sections were double-immunostained for insulin and cleaved (active) caspase-3 before and after 7 days of culture under two-dimensional, CM, or FPCM conditions. The percentage of cleaved caspase-3-positive and insulin-positive islet cells was quantified under the three culture conditions. As expected, the numbers of cleaved caspase-3-positive (apoptotic) islet cells was low in preculture human islets, but increased markedly during 7 days of culture under the two-dimensional condition (Figure 2). The majority of apoptotic cells in cul-

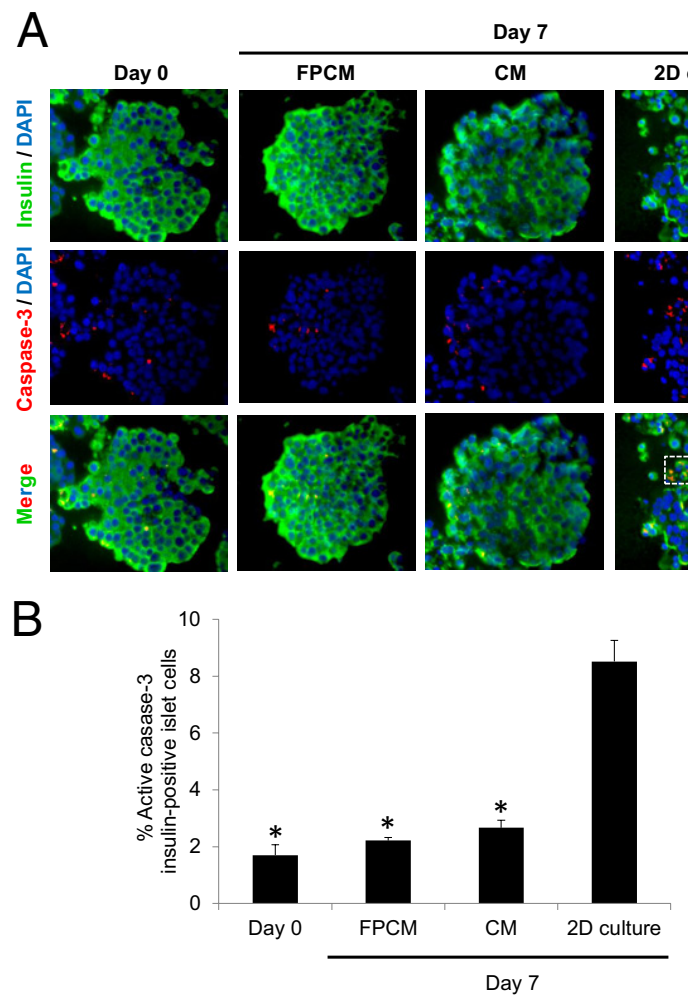

Figure 2. Caspase-3 activation was markedly reduced in islet $\beta$ cells of human islets cultured in three-dimensional scaffolds, compared with twodimensional cultured islets. A: Double immunofluorescence staining for cleaved (active) caspase-3 (red) and insulin (green) of paraffin-embedded human islet sections before (day 0 ) and after 7 days of culture under three different conditions. DAPI was used as a nuclear counterstain. The boxed region corresponds to the inset at higher magnification. B: The number of active caspase-3-positive and insulin-positive islet cells and the total number of $\beta$ cells were counted in islets for each culture condition in a minimum of 20 islets per condition. Data are expressed as means \pm SEM of three independent experiments. ${ }^{*} P<0.05$ versus two-dimensional cultured islets, one-way analysis of variance. Original magnification: $\times 400 ; \times 1000$ (inset) 

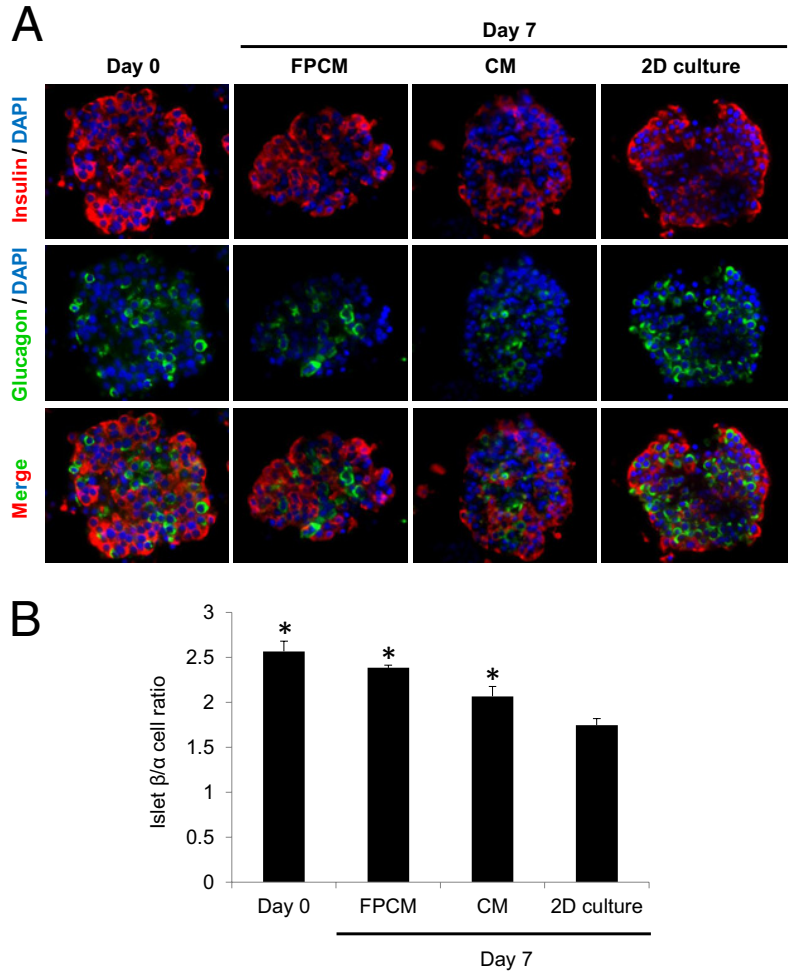

Figure 3. Human islets cultured in three-dimensional scaffolds have higher $\beta / \alpha$ cell ratios, compared with two-dimensional cultured islets. A: Double immunofluorescence staining for insulin (red) and glucagon (green) of paraffin-embedded human islet sections $(5 \mu \mathrm{m})$ before and after 7 days of culture under three different conditions (FPCM, CM, and two-dimensional culture). DAPI was used as a nuclear counterstain. B: Proportion of insulin and glucagon-positive islet cells before and after 7 days of culture. The $\beta / \alpha$ cell ratio was calculated by counting the number of $\beta$ cells and $\alpha$ cells in each islet in a minimum of 40 islets per condition. Data are expressed as means \pm SEM of three independent experiments. ${ }^{*} P<0.01$ versus two-dimensional cultured islets, one-way analysis of variance. Original magnification, $\times 400$.

tured islets were $\beta$ cells. Interestingly, islets embedded within both CM and FPCM had markedly lower numbers of apoptotic $\beta$ cells (Figure 2). This decrease in the number of apoptotic islet $\beta$ cells in CM and FPCM cultured islets was associated with higher numbers of insulinpositive islet cells (Figure $3 \mathrm{~A}$ ) and higher $\beta / \alpha$ cell ratios in $\mathrm{CM}$ - and FPCM-embedded islets, compared with two-dimensional cultured islets (Figure 3B), suggesting that three-dimensional scaffolds reduce $\beta$-cell death and preserve $\beta$-cell viability in human islets during culture. Coculture of human islets with human fibroblasts further reduced $\beta$-cell apoptosis during culture (Figure 3).

\section{Three-Dimensional Scaffolds Preserve Insulin, PDX-1, and GLUT-2 mRNA Expression in Cultured Human Islets}

We tested the effects of three-dimensional scaffolds on mRNA expression of three key $\beta$-cell genes: insulin (INS), pancreatic and duodenal homeobox 1 (PDX1), and solute carrier family 2 (facilitated glucose transporter), member 2 (SLC2A2; previously GLUT2). Islet culture in standard two-dimensional plates resulted in reduced mRNA expression of the genes for insulin, GLUT-2, and PDX-1, but expression was preserved in CM- and FPCM-embedded islets during 7 days of culture. There was no significant difference in mRNA expression of any of these genes between CM- and FPCM-embedded islets (Figure 4).

\section{Three-Dimensional Scaffolds Improve $\beta$-Cell Function in Cultured Human Islets}

We examined the effects of three-dimensional scaffolds on human islet function by assessment of islet insulin response to elevated glucose $(16.7 \mathrm{mmol} / \mathrm{L})$ and insulin content. After 7 days in two-dimensional culture, human islets lost insulin response to elevated glucose and had significantly lower islet insulin content, compared with preculture islets (Figure 5). Embedding human islets within CM partially restored islet insulin response to elevated glucose, and culture in FPCM restored it almost completely (Figure 5A). Furthermore, both $\mathrm{CM}$ - and FPCM-embedded islets had islet insulin content similar to that of preculture islets (Figure 5B). These findings suggest that three-dimensional scaffolds, particularly FPCM, improve $\beta$-cell function, and preserve insulin content in cultured human islets.

\section{Amyloid Formation Is Significantly Less in Human Islets Embedded within Three- Dimensional Scaffolds than Two-Dimensional Cultured Islets}

To examine the effects of three-dimensional scaffolds on islet amyloid formation, human islets were embedded within either CM or FPCM or were cultured in standard two-dimensional culture plates. All culture conditions in-

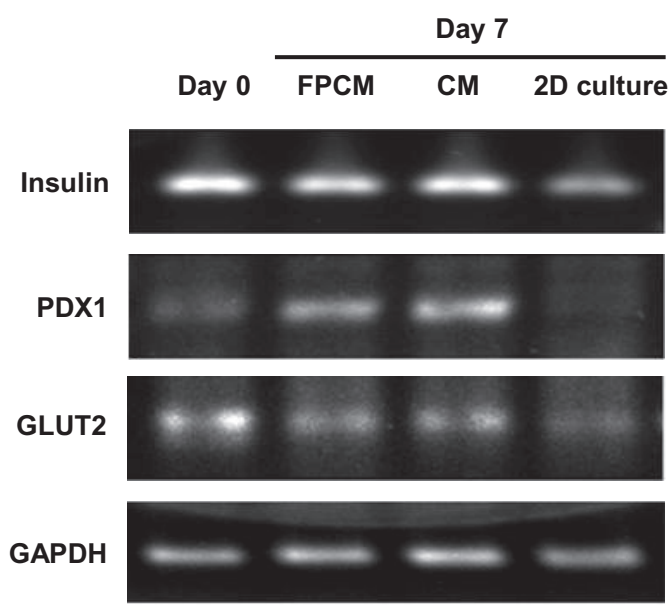

Figure 4. Three-dimensional scaffolds preserve expression of insulin, PDX-1, and GLUT-2 in cultured human islets. Before and after 7 days of culture under three different conditions (CM, FPCM, and two-dimensional culture), expression of insulin, PDX-1, GLUT-2 mRNA in human islets was assessed by performing RT-PCR. Data were normalized to the level of GAPDH mRNA, which was used as internal control. Three-dimensional scaffolds preserved expression of insulin, PDX-1, and GLUT-2 in islet $\beta$ cells during culture. Results are representative of three independent experiments. 

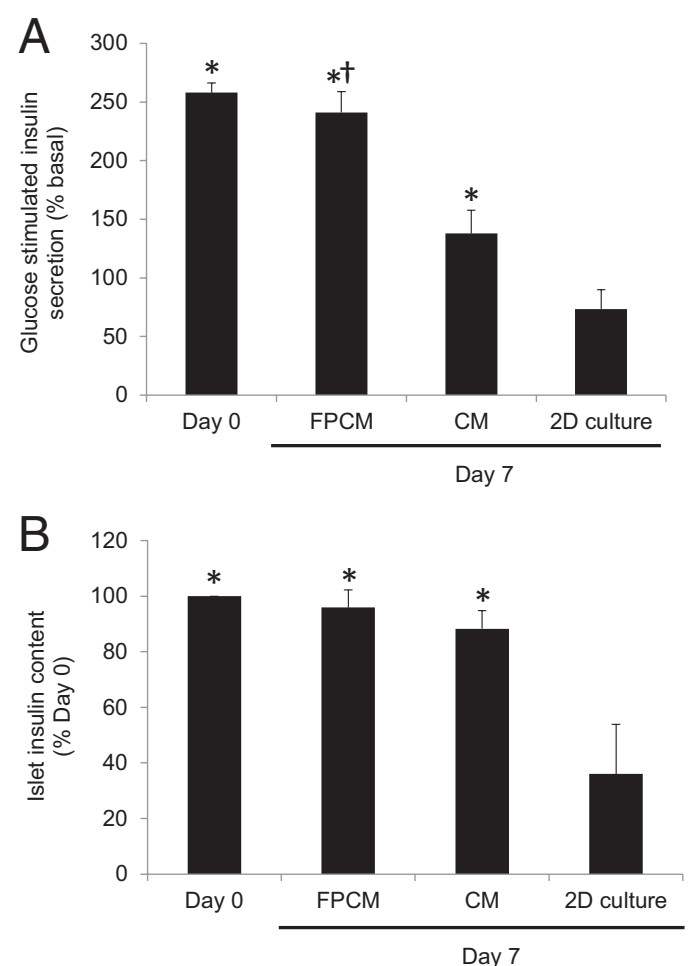

Figure 5. Three-dimensional scaffolds enhance $\beta$-cell function in human islets during in vitro culture. Islet function was assessed by measuring $\mathbf{A}$ : Glucose-stimulated (16.7 mmol/L) insulin secretion and B: islet insulin content in isolated human islets before and after 7 days of culture under three different conditions using a human specific ELISA. Glucose-stimulated insulin secretion was depicted as fold increase over basal release (1.67 $\mathrm{mmol} / \mathrm{L}$ glucose). Islet insulin content was reported as a percentage, with insulin content of preculture (day 0) islets taken as $100 \%$. Islet cultured in three-dimensional CM and FPCM scaffolds had a markedly higher insulin response to elevated glucose and insulin content, compared with twodimensional cultured islets. Maximal islet function was observed in FPCM cultured islets. Results are expressed as means \pm SEM of three independent experiments. ${ }^{*} P<0.05$ versus two-dimensional cultured islets; ${ }^{\dagger} P<$ 0.05 versus CM cultured islets, one-way analysis of variance.

cluded high glucose (16 mmol/L), to potentiate amyloid formation. Paraffin-embedded islet sections from human islets before culture and after culture for 7 days under the three conditions were immunostained for insulin and amyloid (thioflavin S) and the numbers of thioflavin S (amyloid)-positive islets and the islet amyloid area were assessed. Islet amyloid was not detectable in any of the fresh human islet preparations before in vitro culture, but was easily detectable in islets after 7 days of culture under the two-dimensional condition (Figure 6A). Interestingly, islets embedded within CM and FPCM had markedly lower numbers of thioflavin S-positive islets (Figure 6B), as well as significantly lower islet amyloid area compared with two-dimensional cultured islets (Figure 6C). Importantly, FPCM-embedded islets had less amyloid formation than CM-embedded islets, suggesting that collagen matrix and human fibroblasts have additive effects in prevention of amyloid formation in cultured human islets (Figure 6). Sections from human islets before culture and after culture for 7 days under the three conditions (all with $16 \mathrm{mmol} / \mathrm{L}$ glucose concentration) were triple-stained for insulin, cleaved (active) caspase-3, and amyloid (thioflavin S). There was a close correlation be- tween the amyloid-positive and the active capase-3-positive islet $\beta$ cells (Figure 7).

\section{Embedding Human Islets within Three- Dimensional Scaffolds Reduces Islet IL-1 $\beta$ Levels and Fas Expression in Cultured Human Islets}

Sections of human islets embedded within either $\mathrm{CM}$ or FPCM or cultured under the two-dimensional condition (all with $16 \mathrm{mmol} / \mathrm{L}$ glucose concentration) were immunostained for insulin, either IL-1 $\beta$ or Fas, and amyloid (thioflavin S). Consistent with recent findings in other studies, ${ }^{26}$ amyloid deposition in cultured human islets was associated with increased IL-1 $\beta$ levels and up-regulation of the cell death receptor Fas. Interestingly, the lower amyloid formation in human islets cultured in CM or FPCM than in two-dimensional cultured islets was associated with reduced levels of IL-1 $\beta$ and expression of Fas (Figure 8A). We also tested mRNA levels of Fas in human islets before and after culture under different conditions. Similarly, Fas mRNA level was significantly lower in hu-

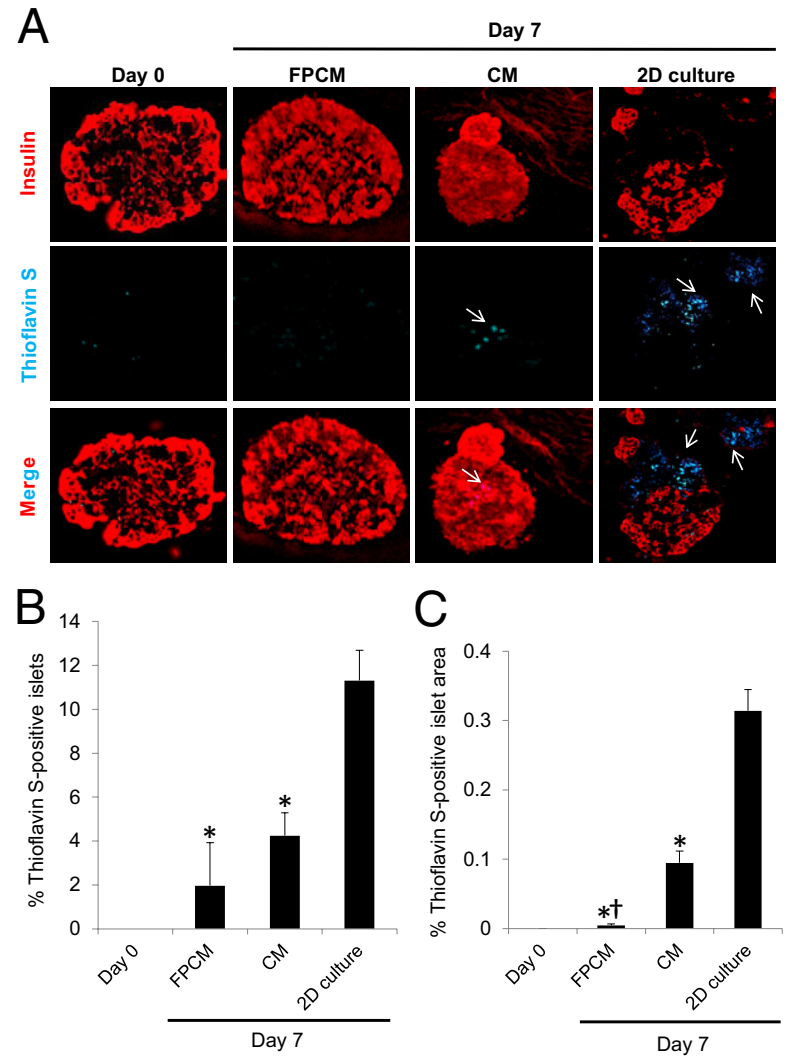

Figure 6. Human islets cultured in three-dimensional scaffolds have markedly reduced islet amyloid formation, compared with two-dimensional cultured islets. A: Double immunostaining of paraffin-embedded islet sections for insulin (red) and thioflavin S (blue) before and after 7 days of culture under three different conditions (CM, FPCM, and two-dimensional culture) with elevated glucose to potentiate amyloid formation (arrows). B and $\mathbf{C}$. Quantification of the number of thioflavin S (amyloid)-positive islets (B) and amyloid-positive islet area $(\mathbf{C})$ in human islets cultured under three different conditions. A minimum of 50 islets per condition were analyzed. ${ }^{*} P<0.01$ versus two-dimensional cultured islets; ${ }^{\dagger} P<0.05$ versus $\mathrm{CM}$ cultured islets, one-way analysis of variance. Original magnification, $\times 400$. 


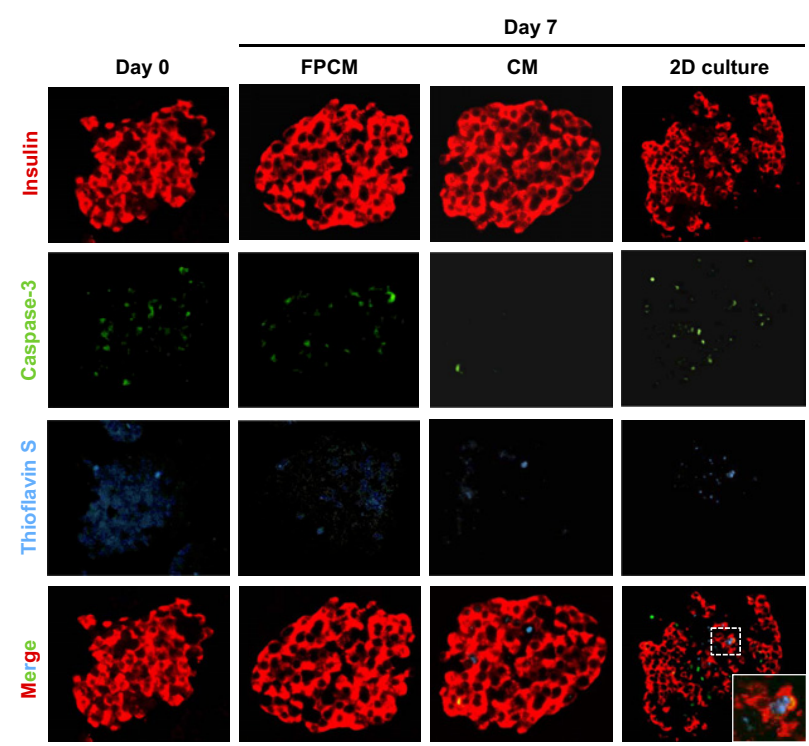

Figure 7. In cultured human islets, amyloid-positive islet $\beta$ cells closely correlate with active caspase-3-positive islet $\beta$ cells. Triple immunofluorescence staining of paraffin-embedded human islet sections $(5 \mu \mathrm{m})$ for insulin (red), cleaved (active) caspase-3 (green), and thioflavin S (blue) before (day 0 ) and after 7 days of culture under three different conditions (FPCM, CM and two-dimensional culture) with elevated glucose to potentiate amyloid formation. The boxed region corresponds to the inset. Original magnification: $\times 400 ; \times 1000$ (inset)

man islets cultured in three-dimensional scaffolds, compared with islets cultured under the two-dimensional condition (Figure 8B).

\section{Discussion}

In the present study, and for the first time to our knowledge, we demonstrated that the three-dimensional scaffolds markedly reduced formation of toxic amyloid aggregates in human islets. We further showed that culture of human islets within the three-dimensional scaffolds markedly improved islet morphology, viability, and function during in vitro pretransplant culture. We believe that these findings are best explained in terms of the three-dimensional scaffolds acting as a surrogate of islet extracellular matrix and thus enhancing islet viability and function.

Adult human islets are surrounded by extracellular matrix, which is closely associated with a capsule consisting of a single layer of fibroblasts and collagen fibers produced by these cells. ${ }^{27}$ Several studies have shown that islet morphology, function, and viability are heavily influenced by the islet extracellular matrix. ${ }^{19-22,28}$ Previous studies have shown that loss of extracellular matrix and disturbances of islet-extracellular matrix interaction caused by islet isolation and culture process are important factors contributing to islet $\beta$-cell dysfunction and death, both during in vitro culture and in islet grafts. ${ }^{23,29,30}$ Accordingly, different approaches have been tested, by our research group and by others, to mimic islet extracellular matrix and to re-establish islet-extracellular matrix interactions. These approaches include using various types of collagen, ${ }^{31,32}$ synthetic polymers, ${ }^{33}$ and small intestinal submucosa ${ }^{34,35}$ as scaffold matrices to improve viability and function of isolated islets and thereby increase the success rate of islet transplantation.

We previously introduced a novel three-dimensional scaffold, consisting of fibroblasts embedded in collagen matrix, to mimic the native extracellular matrix of islets. Our studies suggested that type I collagen is a favorable matrix for our proposed model, compared with other types of collagen matrices, because of its slower biodegradation rate. Type I collagen also provides the natural environment of the fibroblasts that we used in this FPCM scaffold. Additionally, we have previously shown the important role of type I collagen in improving islet viability and function in animal experiments. ${ }^{23,36}$

In the present study, we demonstrated that our proposed three-dimensional scaffolds also successfully enhance the viability and function of human islets during culture in vitro and we further showed that both of the three-dimensional scaffolds (ie, both CM and FPCM) preserve the expression of several key $\beta$-cell genes, including the genes encoding PDX-1 and GLUT-2. PDX-1, a transcription factor, plays a central role in pancreatic $\beta$-cell function and viability by its regulating some other important genes, including insulin, somatostatin, and islet amyloid polypeptide genes. ${ }^{37,38}$ Down-regulation of PDX-1 expression in $\beta$ cells may lead to $\beta$-cell failure in animal models. ${ }^{39}$ In humans, missense mutations of the PDX1 gene result in defective insulin secretion and the development of diabetes. ${ }^{40-43}$ SLC2A2 (encoding GLUT-2) is an important gene for glucose sensing of the pancreatic $\beta$ cell, which participates in the pathway for glucose-stimulated insulin secretion related to islet $\beta$-cell function. ${ }^{44} \mathrm{~A}$ disordered glucose-stimulated insulin release in intrahepatic islets is associated with decreases in the expression of GLUT-2 and of PDX-1. ${ }^{45,46}$ Consistent with these findings, in the present study we demonstrated that both $\mathrm{CM}$ and FPCM preserve expression of PDX-1 and GLUT-2, with enhanced islet viability and function.

Recent studies have shown that islet amyloid, known to be a pathological characteristic of type 2 diabetes mellitus, also forms in cultured and transplanted human islets. ${ }^{11,16,18}$ Early amyloid formation during pretransplant culture of human islets may act as a seed for propagation of further amyloid deposition in islet grafts after transplantation into recipients with type 1 diabetes. ${ }^{17}$ Amyloid formation in islets is associated with $\beta$-cell dysfunction and death, both in vitro and in vivo. ${ }^{11,16,18}$ A growing body of evidence suggests that formation of toxic amyloid in human islets contributes to islet graft failure. ${ }^{16,18,47}$ Reducing amyloid formation, especially at the early stage of amyloid formation during pretransplant islet culture, may thus protect islets from amyloid toxicity and further improve survival of human islets in islet grafts.

One of the key findings of the present study is the demonstration that culture in CM and FPCM markedly reduced islet amyloid formation, compared with two-dimensional culture. Importantly, the effects of FPCM on preventing amyloid formation were more profound than those of CM, suggesting that collagen matrix and fibroblasts have additive effects in prevention of islet amyloid formation. The additive effects of fibroblasts in reducing 
A
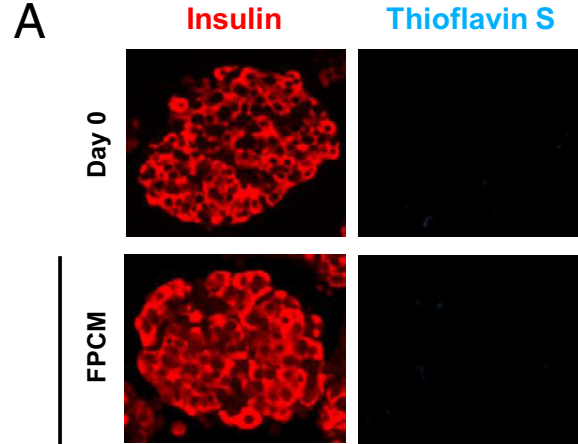

กิ
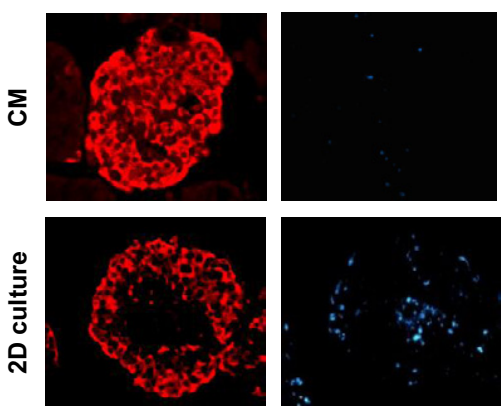

B

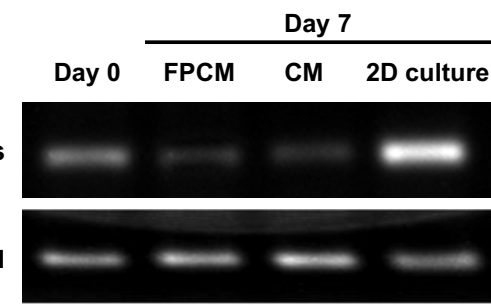

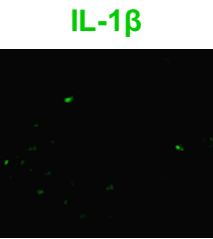
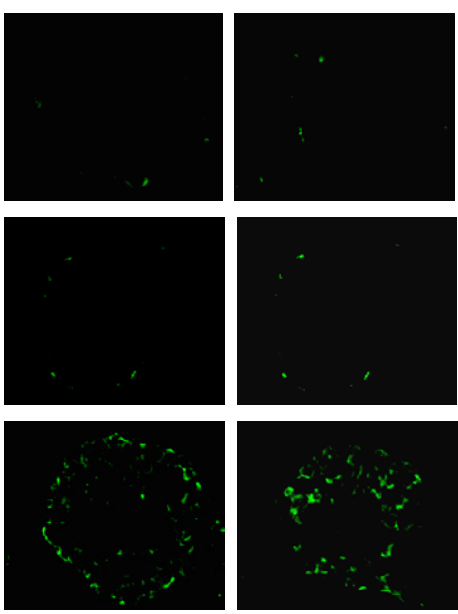

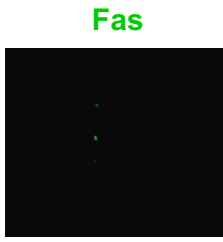

Ins/IL-1 $\beta /$ Thio
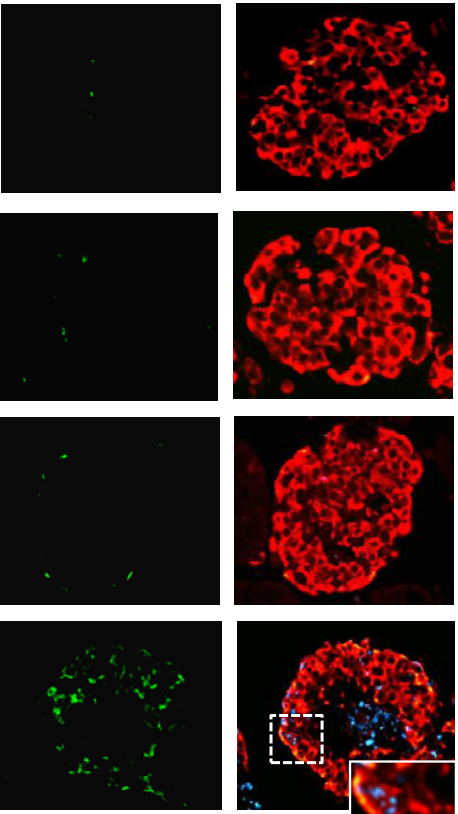

Ins/Fas/Thio
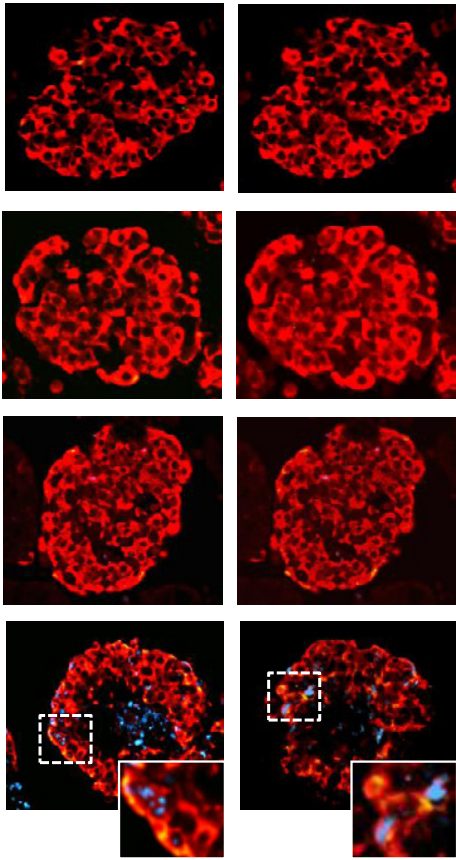

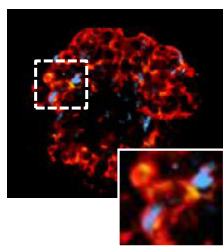

Figure 8. Reduced islet amyloid formation in human islets cultured in three-dimensional scaffolds is associated with lower IL- $1 \beta$ and Fas expression. A: Triple immunofluorescence staining for insulin (red), IL-1 $\beta$ (green) or Fas (green), and thioflavin S (amyloid) (blue) of paraffin-embedded human islet sections $(5 \mu \mathrm{m}$ thick) before and after 7 days of culture under three different conditions (FPCM, CM, and two-dimensional culture) with elevated glucose to potentiate amyloid formation. The boxed regions correspond to the insets. B: Total RNA was isolated from human islets before and after 7 days of culture under three different conditions (FPCM, CM, and twodimensional culture). Expression of Fas mRNA was assessed by performing RT-PCR. Data were normalized to the level of GAPDH mRNA, which was used as internal control. Original magnification: $\times 400 ; \times 1000$ (inset).

amyloid formation in human islets during three-dimensional culture are likely mediated indirectly, via enhanced viability and function of islet $\beta$ cells. Fibroblasts produce fibronectin, which balances synthesis and degradation of matrix and maintains the structural integrity of collagen matrix in FPCM. ${ }^{23}$ Also, previous studies from our research group and those of others have shown that fibroblasts produce and secrete angiogenic factors ${ }^{48}$ and growth factors ${ }^{23,24}$ that can promote islet survival and vascularization.

Recent researches have shown that islet amyloid formation is associated with an increase in IL-1 $\beta$ and upregulation of the cell death receptor Fas. ${ }^{26,49,50}$ For this reason, we evaluated the levels of Fas and $\mathrm{IL}-1 \beta$. Reduced amyloid formation in human islets embedded within three-dimensional scaffolds was associated with lower levels of IL-1 $\beta$ and Fas expression, compared with two-dimensional cultured islets. Taken together, these findings suggest that improving $\beta$-cell viability and function by embedding within three-dimensional scaffolds results in reduced amyloid formation, leading to decreased Fas expression and decreased amyloid-induced $\beta$-cell death in cultured human islets.

Importantly, we speculate that in translational applications of this model, a patient's own fibroblasts could be used for preparation of the three-dimensional scaf- fold to be transplanted. Thus, this model may provide a feasible approach with potential application to clinical islet transplantation. Moreover, we have previously shown that, unlike their rapid proliferation in regular culture medium, fibroblasts have a very low proliferation rate in collagen matrix, ${ }^{23}$ and therefore the islet/ fibroblast ratio does not significantly change during culture in matrix.

In summary, our findings show that embedding human islets within the three-dimensional scaffolds described here decreases amyloid formation and increases viability and function of human islets, and that collagen matrix and fibroblasts have additive effects in enhancing islet function and reducing amyloid formation. These findings provide a new strategy to improve the quality and quantity of human islets, a strategy that could potentially be used in a clinical setting.

\section{Acknowledgments}

We thank Nooshin Safikhan and Dr. Azadeh HosseiniTabatabaei for their help in the GSIS assay and RT-PCR, respectively. 


\section{References}

1. Kay TW, Thomas HE, Harrison LC, Allison J: The beta cell in autoimmune diabetes: many mechanisms and pathways of loss. Trends Endocrinol Metab 2000, 11:11-15

2. Pearl-Yafe M, Yolcu ES, Yaniv I, Stein J, Shirwan H, Askenasy N: The dual role of Fas-ligand as an injury effector and defense strategy in diabetes and islet transplantation. Bioessays 2006, 28:211-222

3. Hogan A, Pileggi A, Ricordi C: Transplantation: current developments and future directions; the future of clinical islet transplantation as a cure for diabetes. Front Biosci 2008, 13:1192-1205

4. Ryan EA, Paty BW, Senior PA, Bigam D, Alfadhli E, Kneteman NM, Lakey JR, Shapiro AM: Five-year follow-up after clinical islet transplantation. Diabetes 2005, 54:2060-2069

5. Shapiro AM, Lakey JR, Ryan EA, Korbutt GS, Toth E, Warnock GL, Kneteman NM, Rajotte RV: Islet transplantation in seven patients with type 1 diabetes mellitus using a glucocorticoid-free immunosuppressive regimen. N Engl J Med 2000, 343:230-238

6. Robertson RP: Islet transplantation a decade later and strategies for filling a half-full glass. Diabetes 2010, 59:1285-1291

7. Robertson RP: Update on transplanting beta cells for reversing type 1 diabetes. Endocrinol Metab Clin North Am 2010, 39:655-667

8. Vaithilingam V, Sundaram G, Tuch BE: Islet cell transplantation. Curr Opin Organ Transplant 2008, 13:633-638

9. Vantyghem MC, Kerr-Conte J, Arnalsteen L, Sergent G, Defrance F, Gmyr V, Declerck N, Raverdy V, Vandewalle B, Pigny P, Noel C, Pattou F: Primary graft function, metabolic control, and graft survival after islet transplantation. Diabetes Care 2009, 32:1473-1478

10. Aikin R, Hanley S, Maysinger D, Lipsett M, Castellarin M, Paraskevas $\mathrm{S}$, Rosenberg L: Autocrine insulin action activates Akt and increases survival of isolated human islets. Diabetologia 2006, 49:2900-2909

11. Marzban L, Tomas A, Becker TC, Rosenberg L, Oberholzer J, Fraser PE, Halban PA, Verchere CB: Small interfering RNA-mediated suppression of proislet amyloid polypeptide expression inhibits islet amyloid formation and enhances survival of human islets in culture. Diabetes 2008, 57:3045-3055

12. Paraskevas S, Duguid WP, Maysinger D, Feldman L, Agapitos D, Rosenberg L: Apoptosis occurs in freshly isolated human islets under standard culture conditions. Transplant Proc 1997, 29:750-752

13. Davalli AM, Scaglia L, Zangen DH, Hollister J, Bonner-Weir S, Weir GC: Vulnerability of islets in the immediate posttransplantation period. Dynamic changes in structure and function. Diabetes 1996, 45:1161-1167

14. Miao G, Ostrowski RP, Mace J, Hough J, Hopper A, Peverini R, Chinnock R, Zhang J, Hathout E: Dynamic production of hypoxiainducible factor-1alpha in early transplanted islets. Am J Transplant 2006, 6:2636-2643

15. Morini S, Brown ML, Cicalese L, Elias G, Carotti S, Gaudio E, Rastellini C: Revascularization and remodelling of pancreatic islets grafted under the kidney capsule. J Anat 2007, 210:565-577

16. Potter KJ, Abedini A, Marek P, Klimek AM, Butterworth S, Driscoll M, Baker R, Nilsson MR, Warnock GL, Oberholzer J, Bertera S, Trucco M, Korbutt GS, Fraser PE, Raleigh DP, Verchere CB: Islet amyloid deposition limits the viability of human islet grafts but not porcine islet grafts. Proc Natl Acad Sci USA 2010, 107:4305-4310

17. Westermark P, Andersson A, Westermark GT: Islet amyloid polypeptide, islet amyloid, and diabetes mellitus. Physiol Rev 2011, 91:795-826

18. Westermark GT, Westermark P, Berne C, Korsgren O; Nordic Network for Clinical Islet Transplantation: Widespread amyloid deposition in transplanted human pancreatic islets. N Engl J Med 2008, 359:977-979

19. Beattie GM, Montgomery AM, Lopez AD, Hao E, Perez B, Just ML, Lakey JR, Hart ME, Hayek A: A novel approach to increase human islet cell mass while preserving beta-cell function. Diabetes 2002, 51:3435-3439

20. Lucas-Clerc C, Massart C, Campion JP, Launois B, Nicol M: Long-term culture of human pancreatic islets in an extracellular matrix: morphological and metabolic effects. Mol Cell Endocrinol 1993, 94:9-20

21. Navarro-Alvarez N, Rivas-Carrillo JD, Soto-Gutierrez A, Yuasa T, Okitsu T, Noguchi H, Matsumoto S, Takei J, Tanaka N, Kobayashi N: Reestablishment of microenvironment is necessary to maintain in vitro and in vivo human islet function. Cell Transplant 2008, 17:111-119

22. Wang RN, Rosenberg L: Maintenance of beta-cell function and survival following islet isolation requires re-establishment of the isletmatrix relationship. J Endocrinol 1999, 163:181-190
23. Jalili RB, Rezakhanlou AM, Hosseini-Tabatabaei A, Ao Z, Warnock GL, Ghahary A: Fibroblast populated collagen matrix promotes islet survival and reduces the number of islets required for diabetes reversal. J Cell Physiol 2011, 226:1813-1819

24. Miki A, Narushima M, Okitsu T, Takeno Y, Soto-Gutierrez A, RivasCarrillo JD, Navarro-Alvarez N, Chen Y, Tanaka K, Noguchi H, Matsumoto S, Kohara M, Lakey JR, Kobayashi E, Tanaka N, Kobayashi $\mathrm{N}$ : Maintenance of mouse, rat, and pig pancreatic islet functions by coculture with human islet-derived fibroblasts. Cell Transplant 2006, 15:325-334

25. Ghahary A, Karimi-Busheri F, Marcoux Y, Li Y, Tredget EE, Taghi Kilani R, Li L, Zheng J, Karami A, Keller BO, Weinfeld M: Keratinocytereleasable stratifin functions as a potent collagenase-stimulating factor in fibroblasts. J Invest Dermatol 2004, 122:1188-1197

26. Park YJ, Lee S, Kieffer TJ, Warnock GL, Safikhan N, Speck M, Hao Z, Woo M, Marzban L: Deletion of Fas protects islet beta cells from cytotoxic effects of human islet amyloid polypeptide. Diabetologia 2012, 55:1035-1047

27. Stendahl JC, Kaufman DB, Stupp SI: Extracellular matrix in pancreatic islets: relevance to scaffold design and transplantation. Cell Transplant 2009, 18:1-12

28. Nagata N, Gu Y, Hori H, Balamurugan AN, Touma M, Kawakami $Y$, Wang W, Baba TT, Satake A, Nozawa M, Tabata Y, Inoue K: Evaluation of insulin secretion of isolated rat islets cultured in extracellular matrix. Cell Transplant 2001, 10:447-451

29. Pinkse GG, Bouwman WP, Jiawan-Lalai R, Terpstra OT, Bruijn JA, de Heer E: Integrin signaling via RGD peptides and anti-beta1 antibodies confers resistance to apoptosis in islets of Langerhans. Diabetes 2006, 55:312-317

30. Rosenberg L, Wang R, Paraskevas S, Maysinger D: Structural and functional changes resulting from islet isolation lead to islet cell death. Surgery 1999, 126:393-398

31. Daoud JT, Petropavlovskaia MS, Patapas JM, Degrandpré CE, Diraddo RW, Rosenberg L, Tabrizian M: Long-term in vitro human pancreatic islet culture using three-dimensional microfabricated scaffolds. Biomaterials 2011, 32:1536-1542

32. Daoud J, Petropavlovskaia M, Rosenberg L, Tabrizian M: The effect of extracellular matrix components on the preservation of human islet function in vitro. Biomaterials 2010, 31:1676-1682

33. Blomeier $\mathrm{H}$, Zhang $X$, Rives $C$, Brissova $M$, Hughes $E$, Baker $M$, Powers AC, Kaufman DB, Shea LD, Lowe WL Jr: Polymer scaffolds as synthetic microenvironments for extrahepatic islet transplantation. Transplantation 2006, 82:452-459

34. Lakey JR, Woods EJ, Zieger MA, Avila JG, Geary WA, Voytik-Harbin SL, Critser JK: Improved islet survival and in vitro function using solubilized small intestinal submucosa. Cell Tissue Bank 2001, 2:217-224

35. Tian XH, Xue WJ, Ding XM, Pang XL, Teng Y, Tian PX, Feng XS: Small intestinal submucosa improves islet survival and function during in vitro culture. World J Gastroenterol 2005, 11:7378-7383

36. Jalili RB, Forouzandeh F, Moeenrezakhanlou A, Rayat GR, Rajotte RV, Uludag $\mathrm{H}$, Ghahary A: Mouse pancreatic islets are resistant to indoleamine 2,3 dioxygenase-induced general control nonderepressible-2 kinase stress pathway and maintain normal viability and function. Am J Pathol 2009, 174:196-205

37. Fujimoto K, Polonsky KS: Pdx1 and other factors that regulate pancreatic $\beta$-cell survival. Diabetes Obes Metab 2009, 11 Suppl 4:30-37

38. Hui $\mathrm{H}$, Perfetti R: Pancreas duodenum homeobox-1 regulates pancreas development during embryogenesis and islet cell function in adulthood. Eur J Endocrinol 2002, 146:129-141

39. Weir GC, Sharma A, Zangen DH, Bonner-Weir S: Transcription factor abnormalities as a cause of beta cell dysfunction in diabetes: a hypothesis. Acta Diabetol 1997, 34:177-184

40. Stoffers DA, Stanojevic V, Habener JF: Insulin promoter factor-1 gene mutation linked to early-onset type 2 diabetes mellitus directs expression of a dominant negative isoprotein. J Clin Invest 1998, 102:232-241

41. Hani EH, Stoffers DA, Chevre JC, Durand E, Stanojevic V, Dina C, Habener JF, Froquel P: Defective mutations in the insulin promoter factor-1 (IPF-1) gene in late-onset type 2 diabetes mellitus. J Clin Invest 1999, 104:R41-R48

42. Clocquet AR, Egan JM, Stoffers DA, Muller DC, Wideman L, Chin GA, Clarke WL, Hanks JB, Habener JF, Elahi D: Impaired insulin secretion and increased insulin sensitivity in familial maturity-onset diabetes of 
the young 4 (insulin promoter factor 1 gene). Diabetes 2000 49:1856-1864

43. Macfarlane WM, Frayling TM, Ellard S, Evans JC, Allen LI, Bulman MP, Ayers S, Shepherd M, Clark P, Millward A, Demaine A, Wilken T, Docherty K, Hattersley AT: Missense mutations in the insulin promoter factor-1 gene predispose to type 2 diabetes. J Clin Invest 1999, 104:R33-R39

44. Cerf ME: High fat diet modulation of glucose sensing in the beta-cell. Med Sci Monit 2007, 13:RA12-RA17

45. Carlsson PO: Influence of microenvironment on engraftment of transplanted beta-cells. Ups J Med Sci 2011, 116:1-7

46. Lau J, Mattsson G, Carlsson C, Nygvist D, Köhler M, Berggren PO, Jansson L, Carlsson PO: Implantation site-dependent dysfunction of transplanted pancreatic islets. Diabetes 2007, 56:1544-1550

47. Udayasankar J, Kodama K, Hull RL, Zraika S, Aston-Mourney K, Subramanian SL, Tong J, Faulenbach MV, Vidal J, Kahn SE: Amyloid formation results in recurrence of hyperglycaemia following transplantation of human IAPP transgenic mouse islets. Diabetologia 2009, 52:145-153

48. Liu H, Chen B, Lilly B: Fibroblasts potentiate blood vessel formation partially through secreted factor TIMP-1. Angiogenesis 2008, 11:223-234

49. Westwell-Roper C, Dai DL, Soukhatcheva G, Potter KJ, van Rooijen N, Ehses JA, Verchere CB: IL-1 blockade attenuates islet amyloid polypeptide-induced proinflammatory cytokine release and pancreatic islet graft dysfunction. J Immunol 2011, 187:2755-2765

50. Masters SL, Dunne A, Subramanian SL, Hull RL, Tannahill GM, Sharp FA, Becker C, Franchi L, Yoshihara E, Chen Z, Mullooly N, Mielke LA Harris J, Coll RC, Mills KH, Mok KH, Newsholme P, Nuñez G, Yodoi J, Kahn SE, Lavelle EC, O'Neill LA: Activation of the NLRP3 inflammasome by islet amyloid polypeptide provides a mechanism for enhanced IL-1beta in type 2 diabetes. Nat Immunol 2010, 11:897904 